\title{
Subcultural grounding of teenage smoking, drinking and use of drugs ${ }^{1}$
}

\author{
GERRIT VAN DER RIJT, LEEN D'HAENENS \\ and PASCALLE VAN STRATEN
}

\section{Abstract}

This study attempts to establish whether subcultures play a part in shaping the smoking behavior and other substance use among teenagers. Written questionnaires were administered among teenagers from 30 school classes aged 12 to $16(N=780)$. Four hypotheses are tested: we expect (1) that teenagers affiliated with counter-cultural styles will have a more positive attitude towards the use of recreational substances, (2) that they are more likely to smoke, drink alcohol, and use soft drugs than members of teenage subcultures which embrace the dominant culture. Also (3) the exchange of cigarettes will be more common in counter-cultural groups than in submissive ones, and (4) teenagers will perceive the different smoking rates in the subcultures according to the actual different rates of tobacco use in these subcultures. Through bi-variate and logistic regression analyses, the research results show that it is very likely that teenage subcultures indeed play a significant role in smoking and other substance (ab) use and that this impact is related to the extent to which these subcultures are counter-culturally oriented. Countercultural teenage groups such as Hiphoppers and Gabbers are relatively more frequent substance users (soft drugs, cigarettes, alcohol) than more parent (dominant)-culture oriented groups such as Normalos, Netjes and Skaters. The watershed is to be found in the counter-cultural use of soft drugs. This seldom studied subcultural dimension of teenage smoking needs to be examined more thoroughly, not only in order to obtain stronger evidence on the matter, but to foster more effective prevention programs aimed at teenagers.

Keywords: smoking behavior, substance use, alcohol consumption, teenage subcultures, lifestyles, dominant culture, counter-cultural identity

\section{Introduction}

In the Netherlands prevention programs seem to have only minor effects on the smoking habits of teenagers. Indeed, the smoking rates among 
teenagers remained almost constant for years, with a recent tendency to grow slightly (Dutch Foundation on Smoking or Health, 1998). The reasons for this are currently unknown. Research has shown that smoking behavior among teenagers is mainly influenced by the smoking behavior of friends, parents and siblings. This (including what goes on with respect to 'the first smoke') has been extensively documented (Van der Rijt, 1979; Morgan and Grube, 1989, 1991; Jackson, 1997, 1998). How this influence is exerted is yet unclear. Possible mechanisms which may account for this influence are the exchange of cigarettes as status-rewarding tools, a similar function to that of sweets in the famous Hawthorne study by Homans (1998). The longitudinal study by Van der Rijt (1979) shows ample evidence that this mechanism actually works in the case of smoking. Group leaders (popular peers) were offered more cigarettes than the rank-and-file, and those who were offered cigarettes on Time 1 were more likely to have started smoking on Time 2 (three months later) than those who had not been offered cigarettes. A second mechanism probably works through attendance to parties. Those teenagers who attended parties (measured at Time 1) more often were more likely to have started smoking between Time 1 and Time 2. A third possible mechanism, and one which has not been studied yet, is the impact of teenage subcultures. Our definition of the concept of subculture refers to the norms, values, and achievements shared by subgroups within society. Teenagers are inclined to identify themselves with various subcultures which are distinguished by such factors as music style, clothing, material and technological accessories, general appearance, and behavior (Hakanan and Wells, 1993; Hebdige, 1991; Larson and Kubey, 1983; Lemish, Drotner, Liebes, Maigret and Stald, 1998; Sun and Lull, 1985, Sikkema, 1988, Wallace and Kovacheva, 1996; van Bork and Jacobs, 1986; van der Rijt, d'Haenens, Jansen and de Vos, 2000). Some teenage subcultures may be more conducive to smoking than others. It is not unlikely that norms sanctioning or prohibiting smoking and cigarette exchange differ across subcultures. Thus in the case of one of such subcultures ('Straight Edge'), it is known that adherents explicitly abstain from or swear off smoking, drinking and the use of drugs. Teenage subcultural subservience may thus be a major explaining factor regarding the failure of prevention programs.

In this study we shall try to establish whether smoking behavior and cigarette exchange rates differ across teenage subcultures. If smoking is a distinct aspect of teenage subcultures and if the latter represent different lifestyles (identity being expressed through a distinct subcultural lifestyle), then we could assume that teenagers perceive such differences in smoking culture and behavior among the various subcultures. Therefore we ask the following question: how do members of various teenage sub- 
cultures view one another's smoking behavior? If smoking is part of the expression of subcultural identity, we can expect a fairly good match between actual and perceived smoking behaviors. Before presenting our research results, we shall discuss some theoretical notions about teenage subcultures and present some hypotheses to be tested. Then we shall describe our research design and operationalizations of key concepts.

\section{Teenage subcultures and lifestyles}

In the seventies, Hebdige (1991) studied the way teenagers expressed themselves through different life styles, concluding: "we had to expand our definition of culture to cover all those expressive forms which give meaningful shape to group experience". He observed that different groups of teenagers developed their own expressive forms in order to create and express their own identity. Some of them did so by rebelling against their culture of origin (working class) or parent culture, establishing their own peculiar position between the one and the other in order to express a different identity, an 'otherness'. For the purposes of our study, the counter-culture/culture of origin (working class)/parent (middle class) culture distinction appears especially relevant. This implies that teenage subcultures develop by coming to terms with and positioning themselves in relation to either the culture of origin or parent culture, or both. The chief characteristic of any teenage subculture will then be whether it adheres to the parent culture or rebels against it and its norms and values. It should be mentioned that the distinction between culture of origin and parent culture is arbitrary, although it is justified in the case of working class culture. While the culture of origin of middle class teenagers is definitely society's dominant culture, Hebdige's viewpoint is bound to be different as he studied working class teenagers, who do perceive their own culture of origin as different from the parent culture. But middle class teenagers do not face such a dichotomy. Thus for the latter, resisting the parent culture means resisting their culture of origin. We assume that some youth subcultures do not aim at opposing themselves against the dominant or parent culture only, but also or mainly against other youth subcultures, especially those youth subcultures associated with the dominant culture. In order to avoid confusion between the concepts of dominant and parent culture, we refer to the dominant culture as to those values, norms and achievements of those groups that are dominant, i.e. most powerful and numerically most important, in society. Parent culture refers to the values, norms and achievements of parents. The latter culture may coincide with the former one, but not necessarily so (as was already made clear in Hebdige's viewpoint on the matter). 
Of course, teenage subcultures are not entirely new cultures, but rather a hodgepodge of elements from the parent culture/culture of origin. Teenagers attempting to develop and express an identity of their own find in teenage subcultures a stylistic frame of reference. According to Brake (1980) teenagers can adhere to one of two sets of values and norms; i.e., one is in accordance with generally accepted norms and values (culture of origin), while the other runs counter to them. This resistance is also apparent in their behavior as well as in the clothes they wear and their tastes in music. To an outside observer, the various teenage subcultures are only recognizable through such pointers: clothing and overall appearance, music preferences, behavior, language and symbol use. Popular music styles seem especially important means of establishing a bond with peers and giving expression to a subcultural identity (Larson and Kubey, 1983; Campbell Robinson, 1986; Roe and Cammaer, 1993; Wallace and Kovacheva, 1996). While music is a crucial element in most teenage subcultures, these often ascertain their own difference by adopting a specific musical style which will then serve as a beacon to attract like-minded members. In other words, styles such as 'mainstream pop', rock, punk, rap and hiphop underlie different subcultures. However, musical taste is not the only outstanding feature of teenage subculture. One is usually confronted with a combination of music, clothing, general appearance and behavior. In the behavioral domain, use of recreational substances (drugs, alcohol and tobacco) may be a distinguishing element; it can be expected that subcultures which rebel against prevailing norms will be more inclined to use substances that are negatively valued by the dominant culture. Although some of these substances (alcohol and tobacco) are widely used in the dominant culture, they are imbued with a negatively valued and especially forbidden to/withheld from teenagers. Teenagers who join subcultures which adhere to the dominant norms and values will abstain from the use of such substances, while counter-cultural oriented teenagers will experience a climate, in which the use of such substances is more rewarding. In counter-cultures there will be a more positive climate regarding substance use, there will be more use of such substances and there will be more exchange of substances.

A longitudinal study involving 2000 teenagers aged 12 to 16 (Van der Rijt, 1980) provided some evidence of smoking as an act of rebellion against parental norms. The study tested the hypothesis that at Time 1 (t1), non-smoking teenagers who were forbidden to smoke by their parents were more likely to have started smoking five months later than non-smoking teenagers under no such prohibition, especially if the parents were themselves smokers. This hypothesis was termed the 'discrimination hypothesis'; i. e., teenagers will feel discriminated against if their 
parents forbid them to do something which they themselves indulge in on a regular basis, and as a result they will disregard the prohibition. The data collected supported the hypothesis perfectly. In fact, it could be that joining a counter-cultural teenage group enhances such rebelliousness.

Therefore, we expect (Hypothesis 1), that teenagers affiliated with counter-cultural styles will have a more positive attitude towards the use of recreational substances. We also expect (Hypothesis 2) that they are more likely to smoke, drink alcohol and use soft drugs than members of teenage subcultures which embrace the dominant culture. Exchange of cigarettes (Hypothesis 3) will be more common in counter-cultural groups than in submissive ones. If smoking is an expression of subcultural identity, and if it is a distinguishing feature of subcultures, then we expect (Hypothesis 4) that teenagers will perceive the different smoking rates in the subcultures according to the actual different rates of tobacco use in the subcultures.

\section{Research design}

\section{Method and sample}

In order to test our hypotheses, data were gathered early 1999, using written questionnaires administered to teenagers aged 12 to 16 by their own teachers, in the classroom. To ensure representativeness, we used a multistage sample. First, 60 institutions were randomly chosen among all Dutch secondary schools. Then six classes per school were randomly selected. Five schools agreed to participate. All participating schools ${ }^{2}$ were public and spread throughout the country. The school population was predominantly white and from Dutch origin. Moreover characteristics such as religion and ethnicity were not taken into account as variables in our study. Thirty classes (780 students) actually completed the questionnaire. While this limited figure adversely affects the sample's representativeness and generalizability, it is sufficient for the purpose of testing the main hypotheses.

\section{Measurement instruments}

This section discusses the operationalization of the main variables. First, in order to identify the subcultural affiliation of the respondents, two methods were used. The first consisted in asking directly which of 11 subcultural groups (Jungle, Hiphop, Skate, Gabber ("mate"), Superboer ("superfarmer"), Punk, Alto, Normalo ("normal"), Metal, Straight Edge, Netjes ("neatly")) suited respondents the best. It should be noted that 
Gabber, Superboer, Normalo and Netjes are specifically Dutch subcultural groups with no exact terminological counterpart anywhere else.

The second method was more indirect; a short description of each subculture was given and respondents were asked to indicate the extent to which they recognized themselves in each subculture (not at all, not quite, to a fair extent, completely). The descriptions were derived from a research-backed inventory of Dutch subcultural styles published in 1997 by Elsevier magazine (van Schoonhoven, 1997: 20-29: the content of these descriptions, can be found in the endnote ${ }^{3}$ ). To test whether the two measurement procedures matched, correlations (gamma) between the direct and indirect identification of each subculture were calculated. Only the five subcultural groups with sufficient members (more than 25) in the sample were used in the analyses. A rest category of remaining subcultures was used as reference category (not included) in the logistic regression analyses. All five correlations appeared to be significant ( $\mathrm{p}<$ $.000)$ and the gamma values were: Hiphop: .565; Gabber: .927; Skate: .642; Normalo: .377; Netjes: .654. So, all the correlations but that for Normalo appeared to be rather strong, meaning that the self-indicated subcultural affiliation fits with the identifications provided in the descriptions. The lower result of the "Normalo" subculture could be explained by the fact that these adolescents were more reluctant to identify themselves with a specific teenage subculture. This reluctance could be derived from comments made by many such as ("I am normal, I don't join a specific group"), actually denying any subcultural adherence.

Our preliminary studies which made use of some in-depth interviews with adolescents indicated that the Hiphop and Gabber subcultures appeared more rebellious against the parent culture,while Normalo and Netjes could be seen as better adjusted to parent culture (working class and middle/upper-class cultures, respectively). The position of the Skate group is somewhat unclear, but probably lies somewhere in between that of the above two categories. In order to test whether such classifications in more or less counter-cultural subcultures have some validity, the relationships of subcultural affiliation with some crucial variables were studied. If a subculture is more counter-cultural, we can expect adherents to be more inclined to violate existing values and norms, more opposed to the school system and regulations, and less bound to their families and parents. In our questionnaire three items were included which could be seen as rough indicators of rejection of/adherence to prevailing norms and values. Table 1 shows the mean scores of the various subcultures on these three indicators.

One-way variance analysis shows that Normalo and Netjes are significantly more inclined to adapt themselves to the existing norms than the three other groups. Also they feel significantly more comfortable at 
Table 1: Parent culture indicators ${ }^{1}$ ) and mean scores ${ }^{2}$ ) for the different subcultures

\begin{tabular}{|c|c|c|c|c|c|c|}
\hline $\begin{array}{l}\text { Subcultural affiliation } \\
\text { (Superscript marks) } \\
\text { Statements }\end{array}$ & $\begin{array}{l}\text { Hiphop } \\
\text { H }\end{array}$ & $\begin{array}{l}\text { Gabber } \\
\mathrm{g}\end{array}$ & $\begin{array}{l}\text { Skate } \\
\text { s }\end{array}$ & $\begin{array}{l}\text { Normalo } \\
\text { no }\end{array}$ & $\begin{array}{l}\text { Netjes } \\
\mathrm{Ne}\end{array}$ & Sig. \\
\hline $\begin{array}{l}\text { I get along with my } \\
\text { parents very well }\end{array}$ & 4.72 & 4.59 & 5.23 & 5.09 & 5.24 & .002 \\
\hline I feel good at school & 4.07 & $3.45^{\text {no,ne }}$ & 4.22 & 4.37 & 4.57 & .002 \\
\hline I never break the law & $2.59^{\text {no,ne }}$ & $3.00^{\text {no, ne }}$ & $2.82^{\text {no,ne }}$ & 3.47 & 3.69 & .000 \\
\hline $\mathrm{N}$ & 61 & 83 & 29 & 390 & 102 & \\
\hline
\end{tabular}

1) Scale scores range from 1 (agrees not at all) to 6 (agrees completely).

$\left.{ }^{2}\right)$ Superscripts indicate significant $(\mathrm{p}<.05)$ differences between the group under scrutiny and the groups indicated by means of their superscript marks, tested by one-way variance post hoc test (Scheffe).

school than Gabbers. Moreover, the Normalo and Netjes groups score higher than the Skaters and Hiphoppers on the latter item. Together the Normalos and the Netjes group score significantly higher $($ mean $=4.41)$ than the other three groups together $($ mean $=4.03)$. The Normalo and Netjes group, as well as the Skaters, also seem to get along better with their parents than the Gabbers and Hiphoppers. A t-test revealed that the difference in mean between the Skate, Normalo and Netjes subcultural groups $($ mean $=5.13)$ on the one hand and Gabber and Hiphop (mean $=4.68)$ on the other was significant $(\mathrm{t}=3.35, \mathrm{df}=109.18, \mathrm{p}=$ $.001)$. These findings support the assumption that Normalo and Netjes are more parent-culture oriented than Gabbers and Hiphop, with the Skaters occupying the middle ground. Nevertheless, taking into consideration the position of Skate on the third item (law breaking), which is to be seen as the more evident indicator for counter-culture, it could be argued that Skaters are about the same as Gabbers and Hiphoppers on the counter-cultural scale.

Smoking behavior is measured by two variables based on self-reported behavior: "Has tried smoking" (yes/no) and "Smokes daily" (yes/no). Alcohol use is measured by one item: "(sometimes) drinks alcohol" (yes/ no). Soft drug use is also measured by one item: "(sometimes) uses soft drugs" (yes/no). The exchange of cigarettes is measured by two questions: "Do you offer your friends (self-rolled) cigarettes?" (never, sometimes, often) and "Do your friends offer you (self-rolled) cigarettes?" (never, sometimes, often).

Another concept that may be indicative of a substance use furthering climate in subcultures is a positive attitude towards such substances. Four items in our questionnaire could be taken as indicative for such an attitude: "Smoking is pleasant"; "Alcohol favors pleasant companion- 
ship with others"; "By using XTC, things become even more comfortable"; "Smoking is a sign of adulthood" (1. "agrees not at all" to 6 . "agrees completely"). A factor analysis revealed that these four items represent one dimension. Factor scores were used as scale values. The reliability of the scale was moderate $(\alpha=.60)$.

The perception of a different smoking climate in different subcultures is measured by the question: "Please indicate for each of the following teenage groups (Hiphop, Gabber, Skate, Normalo, Netjes) whether you think that smoking suits that particular group? (smoking does suit/ doesn't suit/don't know).

In order to rule out some alternative explanations for the role of subcultural affiliation three possible confounders are included: sex, age, and educational level - low (vocational), middle (lower general secondary), high (general secondary and pre-university). Educational level is known to be a major determinant of smoking behavior among adolescents: the higher the educational level, the lower the smoking rates (Van der Rijt, 1979).

\section{Results}

Bivariate results regarding the first hypothesis are provided in table 2. This table shows that the results support the hypotheses. Subcultures differ significantly in substance use, cigarette exchange behavior, and positive orientation towards substance use. Hiphoppers and Gabbers include the highest numbers of users/exchangers, while Normalos and

Table 2: Smoking behavior, alcohol and soft drugs use (self-reported), cigarette exchange behavior and positive orientation towards the use of substances in teenage subcultures

\begin{tabular}{|c|c|c|c|c|c|c|c|c|}
\hline & Hiphop & Gabber & Skate & Normalo & Netjes & $\mathrm{Chi}^{2}$ & df & Sig. \\
\hline Has tried smoking & $80 \%$ & $83 \%$ & $55 \%$ & $47 \%$ & $51 \%$ & 34.17 & 4 & .000 \\
\hline Smokes daily & $20 \%$ & $31 \%$ & $5 \%$ & $6 \%$ & $12 \%$ & 35.05 & 4 & .000 \\
\hline Drinks alcohol & $75 \%$ & $89 \%$ & $71 \%$ & $64 \%$ & $65 \%$ & 10.54 & 4 & .032 \\
\hline Uses soft drugs & $23 \%$ & $17 \%$ & $7 \%$ & $3 \%$ & $1 \%$ & 53.58 & 4 & .000 \\
\hline Offers cigarettes to friends & $44 \%$ & $38 \%$ & $15 \%$ & $12 \%$ & $21 \%$ & 47.67 & 4 & .000 \\
\hline Friends offer cigarettes & $75 \%$ & $69 \%$ & $42 \%$ & $43 \%$ & $52 \%$ & 29.81 & 4 & .000 \\
\hline $\begin{array}{l}\text { Positive orientation } \\
\text { towards the use of sub- } \\
\text { stances (mean score on }\end{array}$ & & & & & & $\begin{array}{l}\text { One wa } \\
\text { F }\end{array}$ & ay & \\
\hline factor) ${ }^{1}$ ) & $.503^{\mathrm{s}, \mathrm{no}, \mathrm{ne}}$ & $.493^{\text {no,ne }}$ & .034 & -.099 & -.180 & 12.84 & 4 & .000 \\
\hline Total $(\mathrm{N})$ & 64 & 29 & 88 & 394 & 102 & & & \\
\hline
\end{tabular}

$\left.{ }^{1}\right)$ Superscripts indicate significant $(\mathrm{p}<.05)$ differences between the group under scrutiny and the groups indicated by means of their superscript marks, tested by one-way variance post hoc test (Scheffe). 
Netjes show much lower rates for smoking or exchanging cigarettes. In terms of the subcultures under scrutiny, our main hypothesis - that counter-cultural subcultures use more substances and exchange more cigarettes, and are therefore a rich breeding ground for substance use is clearly supported. Skaters, on the other hand, seem more in tune with parent-culture oriented subcultures; they score even lower on daily smoking. As seen in table 1, they get along very well with their parents, at least in comparison with the Normalo and Netjes groups, which pleads in favor of a parent culture orientation. Moreover, considering the fact that this subculture evolves around a sport (skating), it seems only natural that its members should value healthy behavior. Looking more closely at the results, we observe that alcohol use is more common in all subcultures than smoking and soft drug use. Regarding alcohol use, the differences among the subcultures are less pronounced, as indicated by the relatively low chi square value. The differences between subcultures are by far the most pronounced in the case of soft drugs use. These findings are rather easy to explain from a counter-cultural perspective; while alcohol consumption (unless excessive) is very common and rather positively valued in the dominant culture (albeit not allowed for younger teenagers), soft drugs use is not allowed at all.

All in all it seems that soft drugs provide an excellent opportunity to express counter-cultural identity. Smoking falls in between the other two substance types; i. e., while not uncommon in the dominant parent culture, smoking is valued very negatively and especially forbidden to children by the dominant culture, which again could provide an opportunity to express counter-cultural feelings. Therefore, the data fit the cultural values order exceedingly well. In order to establish the impact of subcultures on substance use, etc., more unambiguously (without other factors clouding the picture), logistic regression analyses were carried out regarding the dichotomous dependents. A regular regression analysis (with dummy variables) was also carried out regarding the interval measure. Three control variables were included: age, sex and educational level. The results of these analyses are displayed in table 3.

Results indicate that subcultural affiliation indeed has a significant impact on all of the dependents. Looking at the impact of the different subcultures (the $\mathrm{B}$ coefficients of the logistic regression and the beta coefficients for the regular regression) the results are in general similar to those of the bi-variate analyses from table 2 and therefore also support the first three hypotheses.

Regarding the fourth hypothesis, we expected teenagers to perceive the varying levels of tobacco use in the different subcultures in accordance with the various, actual uses. The perception of alcohol and soft drugs use was however not included in our research, since our primary 


\section{Gerrit van der Rijt, Leen d'Haenens and Pascalle van Straten}

Table 3: Logistic regression of dependent variables ("Has tried smoking", "Smokes daily", "Drinks alcohol", "Uses soft drugs", "Offers cigarettes to friends", "Friends offer cigarettes") on independent variables (gender, educational level, age, subcultural affiliation) and regression of positive orientation towards substances to the same independent variables.

\begin{tabular}{|c|c|c|c|c|c|c|}
\hline $\begin{array}{l}\text { Has tried } \\
\text { smoking }\end{array}$ & $\begin{array}{l}\text { Smokes } \\
\text { daily }\end{array}$ & $\begin{array}{l}\text { Drinks } \\
\text { alcohol }\end{array}$ & $\begin{array}{l}\text { Uses soft } \\
\text { Drugs }\end{array}$ & $\begin{array}{l}\text { Offers } \\
\text { cigarettes } \\
\text { to friends }\end{array}$ & $\begin{array}{l}\text { Friends } \\
\text { offer ci- } \\
\text { garettes }\end{array}$ & $\begin{array}{l}\text { Positive } \\
\text { orientation } \\
\text { towards } \\
\text { substances }\end{array}$ \\
\hline
\end{tabular}

\begin{tabular}{|c|c|c|c|c|c|c|c|c|}
\hline \multicolumn{9}{|l|}{ Gender } \\
\hline B & -.234 & .356 & .063 & .904 & -.026 & -.379 & $\beta$ & -.090 \\
\hline Wald (df 1 ) & 1.895 & 1.413 & .114 & 5.283 & .014 & 4.760 & $\mathrm{t}$ & -2.376 \\
\hline Sig. & .169 & .238 & .736 & .022 & .907 & .029 & Sig. & .018 \\
\hline \multicolumn{9}{|l|}{$\begin{array}{l}\text { Educational } \\
\text { level }\end{array}$} \\
\hline B & -.349 & -.863 & -.356 & -.473 & -.521 & -.453 & $\beta$ & -.086 \\
\hline Wald (df 1 ) & 12.681 & 19.202 & 10.762 & 4.429 & 15.280 & 20.403 & $\mathrm{t}$ & 2.376 \\
\hline Sig. & .000 & .000 & .001 & .035 & .000 & .000 & Sig. & .018 \\
\hline \multicolumn{9}{|l|}{ Age } \\
\hline B & .361 & .501 & .735 & .734 & .497 & .498 & $\beta$ & .110 \\
\hline Wald (df 1 ) & 18.747 & 11.308 & 54.575 & 16.565 & 20.695 & 33.742 & $\mathrm{t}$ & 3.061 \\
\hline Sig. & .000 & .001 & .000 & .000 & .000 & .000 & Sig. & .002 \\
\hline \multicolumn{9}{|l|}{ Hiphop } \\
\hline B & 1.148 & .334 & -.378 & .815 & .659 & .747 & $\beta$ & .133 \\
\hline Wald (df 1 ) & 7.864 & .416 & .730 & 2.396 & 2.650 & 3.532 & $\mathrm{t}$ & 2.987 \\
\hline Sig. & .005 & .519 & .393 & .122 & .104 & .060 & Sig. & .003 \\
\hline \multicolumn{9}{|l|}{ Gabber } \\
\hline B & 1.357 & .660 & .520 & .141 & .350 & .441 & $\beta$ & .076 \\
\hline Wald (df 1 ) & 5.968 & 1.303 & .548 & .047 & .489 & .828 & $\mathrm{t}$ & 1.885 \\
\hline Sig. & .015 & .254 & .459 & .829 & .484 & .363 & Sig. & .060 \\
\hline \multicolumn{9}{|l|}{ Skate } \\
\hline B & .273 & -1.468 & -.278 & -.790 & -.736 & -.537 & $\beta$ & -.023 \\
\hline Wald (df 1 ) & .668 & 4.316 & .480 & 1.593 & 2.801 & 2.443 & & -.504 \\
\hline Sig. & .414 & .038 & .489 & .207 & .094 & .118 & Sig. & .615 \\
\hline \multicolumn{9}{|l|}{ Normalo } \\
\hline B & -.299 & -.898 & -.744 & -1.392 & -.913 & -.639 & $\beta$ & -.093 \\
\hline Wald (df 1) & 1.317 & 4.125 & 5.484 & 7.309 & 7.724 & 5.739 & & -1.657 \\
\hline Sig. & .251 & .042 & .019 & .007 & .005 & .017 & Sig. & $\begin{array}{l}. \quad .098 \\
\end{array}$ \\
\hline Netjes $B$ & -.360 & -.543 & -.920 & -2.529 & -.519 & -.463 & $\beta$ & -.109 \\
\hline Wald (df 1 ) & 1.277 & 1.071 & 5.936 & 5.406 & 1.741 & 2.026 & $\mathrm{t}$ & -2.284 \\
\hline Sig. & .259 & .301 & .015 & .020 & .187 & .155 & Sig. & $\begin{array}{r}. \quad .023 \\
\end{array}$ \\
\hline \multirow{2}{*}{\multicolumn{9}{|c|}{$\begin{array}{l}\text { Tot. Eff. } \\
\text { Subcult. Aff. }\end{array}$}} \\
\hline & & & & & & & & \\
\hline Wald (df 5) & 27.745 & 18.336 & 11.771 & 27.104 & 28.060 & 23.919 & & \\
\hline Sig. & .000 & .003 & .038 & .000 & .000 & .000 & & \\
\hline $\begin{array}{l}\text { Nagelkerke } \\
\mathrm{R}^{2}\end{array}$ & .123 & .178 & .174 & .242 & .153 & .157 & Adj. & $\mathrm{R}^{2} .088$ \\
\hline
\end{tabular}


Table 4: Perceptions of teenagers as to whether smoking suits a given subculture

\begin{tabular}{lrrrrrrrrr}
\hline $\begin{array}{l}\text { Smoking } \\
\text { suits: }\end{array}$ & Hiphop & Gabber & Skate & Normalo & Netjes & Total & $\mathrm{Chi}^{2}$ & df & Sig. \\
\hline Gabber & $88 \%$ & $89 \%$ & $96 \%$ & $96 \%$ & $93 \%$ & $95 \%$ & 9.03 & 4 & .060 \\
Hiphop & $78 \%$ & $75 \%$ & $67 \%$ & $69 \%$ & $66 \%$ & $69 \%$ & 2.86 & 4 & .581 \\
Skate & $77 \%$ & $64 \%$ & $60 \%$ & $64 \%$ & $47 \%$ & $62 \%$ & 15.42 & 4 & .004 \\
Normalo & $41 \%$ & $37 \%$ & $17 \%$ & $28 \%$ & $30 \%$ & $28 \%$ & 9.25 & 4 & .049 \\
Netjes & $3 \%$ & $4 \%$ & $7 \%$ & $7 \%$ & $11 \%$ & $7 \%$ & 3.44 & 4 & .488 \\
\hline
\end{tabular}

aim was to establish a relationship between youth subcultures and smoking. Therefore results were limited to smoking (see table 4). Looking at the totals we observe a declining order of percentage of teenagers who think smoking suits particular subcultures. Nearly all think that the Gabber subculture suits smoking, while only $7 \%$ think that the same goes for the Netjes group. Regarding these two groups, no significant difference between the members of the various subcultures could be detected in this matter. We can observe also that the counter-culture oriented groups (Gabber and Hiphop) are perceived as smoking-friendly more frequently than the parent-culture oriented groups (Normalo and Netjes). So, in broad terms, results seem to support our hypothesis. Thus at the top of our smoking-friendly scale are the Gabber and Hiphop groups, followed by Skate, Netjes and Normalo ("Has tried smoking") or by Netjes, Normalo and Skate ("Smokes daily").

We came across two contradictory results. Skaters seem to have a more negative image regarding smoking than indicated by the actual smoking rates, and this image prevails in the Skate subculture itself. The Netjes group scores lowest on the image of smoking and has thus a more positive image than the actual smoking rates indicate, particularly in the counter-cultural subcultures. Since this image is nearly uniform across subcultures, there are two possible explanations; first, our sample included a very high number of smokers as compared to the actual 'membership' of this subculture; also, teenagers belonging to this group are supposed to follow parental norms more closely than they actually do. Future research may be able to establish which explanation is the correct one. The discrepancy regarding Skaters is harder to explain. The Skate culture has the image of a smoking subculture. Yet actual smoking rates are the lowest of all.

All data indicate that Skaters are closer to the parent-culture oriented groups than Hip-hoppers and Gabbers. Two factors may be responsible for this discrepancy. Although Skaters seem more open to substance use (group norm) than Normalos and Netjes, they may be more inclined to give in to parental disapproval of such habits. This explanation could 
also explain the relatively high score of the "Has tried smoking" variable as compared with the low score of "Smokes daily"; they may have quit smoking more often because of parental pressure. Another possible explanation is that, while the subculture as such is not against smoking, its emphasis on sports may encourage individuals to abstain from it. More conclusive data can only come from further research. In spite of these unexpected deviations, our research hypotheses appear to be quite correct. We can conclude that it is plausible that teenage subcultures indeed play a significant role in fostering or limiting smoking and other substance use.

\section{Discussion}

Our aim was to show that youth subcultures have a varying impact on substance use among teenagers, and that this is related to the extent to which they are counter-culturally oriented. Both hypotheses were supported by the data. Counter-cultural teenage groups such as Hiphoppers and Gabbers are relatively more frequent substance users (soft drugs, cigarettes, alcohol) than more parent-culture oriented groups such as Normalos, Netjes and Skaters. The watershed is to be found in the clearly counter-cultural - use of soft drugs. Thus, as could be expected, teenage subcultures as a whole appear to foster substance use among their members, although those groups that are more steeped in parentculture values and norms seem to have the opposite effect. These findings also support the premises of the Hiphop culture approach regarding campaigning against smoking as presented by Sterlen Barr and Chary Sutton ("Hiphop and Smoking", 2000) on the occasion of the 11th Tobacco OR Health World Conference in Chicago. They saw Hiphoppers as a counter-cultural oriented group and smoking as a sign of rebellion against the dominant (parent) culture. Their notion of redirecting the expression of such rebelliousness from smoking to counter-cultural attacks against the tobacco industry viewed as a representative of the dominant culture is probably somewhat simplistic. It assumes that any counter-cultural stance can simply be replaced by another, which would make the fight against substance abuse seemingly very easy. But it also makes a very important point for health educators and prevention programs targeting counter-cultural groups; they need to take into account the counter-cultural significance of substance abuse in the mind of the members of such groups.

Behavioral patterns of youngsters seem to correlate highly with their subcultural affiliation. Especially the fact that this correlation evolves along the lines of opposite subcultures - opposite to each other but also to the dominant culture - suggests that subcultures are paramount in 
the lives of youngsters and are as such important factors fostering behavioral patterns, especially those patterns that are related to addictional behavior, and therefore influencing their future lives. It seems therefore necessary to study these phenomena in both a more in-depth and extensive fashion, adopting a research design that is better suited for causal inferences than ours. This would provide us with more certainty and clarity when designing more effective interventions targeted at the diverse youth groups.

As the most likely to suffer from substance abuse, teenage groups with a counter-cultural bent should be the first target for prevention. But traditional prevention programs, which presumably have the intended effect on parent-culture oriented groups, may well only serve to reinforce rebellious behavior among the others. Indeed, this virtually unknown dimension of teenage smoking will have to be investigated much more thoroughly for prevention to achieve consistent results. Any prevention program must be based on the values, norms and utterances prevailing in the target subculture. A good example is Sterlen Barr's approach, which strives to promote healthy behaviors among teenagers using rap music as its primary communication tool. But evaluation research would need to establish whether, and if so, to what extent, an approach based on subcultural features indeed pays better dividends when applied to counter-cultural subcultures.

This study, however, cannot offer definitive proof of the influence of subcultures on smoking behavior, because the design is cross-sectional. A longitudinal research design would have been more suited for our aim. This study only attempts to establish whether subcultures may plausibly play a part in shaping the smoking behavior of teenagers. It is also conceivable, however that, instead of subcultures influencing youngsters, the latter choose the subculture which corresponds best with their behavior.

\section{Notes}

1. A substantially shortened version of the present article, entitled "Smoking and other substance use as distinct features of teenage subcultures" by G. van der Rijt, L. d'Haenens and P. van Straten was published in the Journal of Adolescent Health, Volume 31, 2002, pp. 433-435. Elsevier Science/The Society for Adolescent Medicine granted the authors permission to reproduce the aforementioned article, which is part of the present full version

2. Schools participating in our study are: Openbare Scholengemeenschap Esdal College (Emmen, North of the country, urban area); Regionale Scholengemeenschap Brokleden (Breukelen, centre of the country, rural area); Koninklijke Scholengemeenschap (Apeldoorn, centre of the country, urban area); Meerwegen College (Amersfoort, centre, urban), and Scholengemeenschap Nassau (Breda, South, urban). 
3. Hiphop: "I love Rhythm and Blues and Nederhop music. I prefer ample shirts and pants and high Nikes. I love golden chains and the clothes I wear are almost always new."

Gabber: "I love gabber music, I preferably wear a training suit (for instance from the brand called Australian), jeans and Nikes. I spend quite a bit of money on my clothes."

Skate: "I love R\&B and guitar music. I mostly wear long-sleeved t-shirts under normal t-shirts together with ample pants and sneakers."

Normalo: "I like all kinds of music and I don't have a specific preference for particular clothes, but it shouldn't catch the eye too much."

Netjes: "I care for a neat appearance. I will never wear sportswear or white socks outside the sports club. I prefer to wear leather shoes, nice pants or jeans and a neat t-shirt or sweatshirt. I spend rather much money on my clothes."

\section{References}

Barr, S. and Sutton, C. (2000). Hiphop and Smoking. Presentation at the $11^{\text {th }}$ tobacco OR Health World Conference, Chicago, Ill..

Bork, R. J. van and Jacobs, J. C. F. (1986). Popmuziek: het geluid van jongeren [Pop Music: The Sound of Teenagers]. Muiderberg: Coutinho.

Brake, M. (1980). The Sociology of Youth Culture and Youth Subcultures. London: Routledge and Keegan Paul.

Campbell Robinson, D. (1986). Teenagers and popular music: A theoretical rationale for an international study. Gazette, 37, 33-50.

Dutch Foundation on Smoking or Health (1998). Jaarverslag [Year Report]. The Hague: Stivoro.

Hebdige, D. (1991). Subculture. The Meaning of Style. London: Routledge.

Hakanan, E. A. and Wells, A. (1993). Music preference and taste cultures among adolescents, Popular Music and Society, 17 (1), 55-69.

Homans, G. C. (1998). The Human Group. London: Routledge.

Jackson, C. (1997). Initial and experimental stages of tobacco and alcohol use during late childhood: Relation to peer, parent, and personal risk factors, Addictive Behaviours, 22 (5), 685-698.

Jackson, C. (1998). Cognitive susceptibility to smoking and initiation of smoking during childhood: A longitudinal study, Preventive Medicine, 27, 129-134.

Larson, R. and Kubey, R. (1983). Television and music: Contrasting media in adolescent life, Teenagers and Society, 15 (1), 13-31.

Lemish, D., Drotner, K., Liebes, T., Maigret, E., and Stald, G. (1998). Global culture in practice: A look at adolescents in Denmark, France and Israel. The European Journal of Communication, 13 (4), 539-556.

Morgan, M. and Grube, J. W. (1989). Adolescent cigarette smoking: A developmental analysis of influences. British Journal of Developmental Psychology, 7, 179-189.

Morgan, M. and Grube, J. W. (1991). Closeness and peer group influence. British Journal of Social Psychology, 30, 159-169.

Rijt, G. A. J. van der (1979). Jeugd en antirookinformatie [Youth and Anti-Smoking Information]. Nijmegen: ITS.

Rijt, G. A. J. van der (1980). Verbieden of voorlichten? Evaluatie van alternative strategieën voor de bestrijding van het roken door jongeren (Forbidding or educating: An evaluation of alternative strategies for the struggle against smoking by youngsters). Tijdschrift voor Alcohol en Drugs, 6 (2), 61-68.

Rijt, G. A. J. van der, d'Haenens, L., Jansen, R. H. A., and de Vos, C. J. (2000). Young people and music television in the Netherlands. European Journal of Communication, 15 (1), 79-91. 
Roe, K. and Cammaer, G. (1993). Delivering the young audience to advertisers: Music television and Flemish teenagers. Communications, 18, 169-177.

Schoonhoven, G. van (1997). Jeugd van tegenwoordig [Youth Today], Elsevier, 53 (7), 20-29.

Sikkema, P. (1988). Jeugd nu [Youth Now]. The Hague: SDU.

Sun, S and Lull, J. (1985). The adolescent audience for music videos and why they watch? Journal of Communication, 36, 115-125.

Wallace, C. and Kovacheva, K. (1996). Teenagers cultures and consumption in Eastern and Western Europe, an overview. Teenagers and Society, 28, 189-214. 